\title{
Article
}

\section{Electrochemical Stability of Metastable Materials}

Arunima K. Singh, Lan Zhou, Aniketa Shinde, Santosh K Suram, Joseph

H. Montoya, Donald Winston, John M. Gregoire, and Kristin A. Persson

Chem. Mater., Just Accepted Manuscript • DOI: 10.1021/acs.chemmater.7b03980 • Publication Date (Web): 24 Oct 2017

Downloaded from http://pubs.acs.org on October 24, 2017

\section{Just Accepted}

"Just Accepted" manuscripts have been peer-reviewed and accepted for publication. They are posted online prior to technical editing, formatting for publication and author proofing. The American Chemical Society provides "Just Accepted" as a free service to the research community to expedite the dissemination of scientific material as soon as possible after acceptance. "Just Accepted" manuscripts appear in full in PDF format accompanied by an HTML abstract. "Just Accepted" manuscripts have been fully peer reviewed, but should not be considered the official version of record. They are accessible to all readers and citable by the Digital Object Identifier (DOI®). "Just Accepted" is an optional service offered to authors. Therefore, the "Just Accepted" Web site may not include all articles that will be published in the journal. After a manuscript is technically edited and formatted, it will be removed from the "Just Accepted" Web site and published as an ASAP article. Note that technical editing may introduce minor changes to the manuscript text and/or graphics which could affect content, and all legal disclaimers and ethical guidelines that apply to the journal pertain. ACS cannot be held responsible for errors or consequences arising from the use of information contained in these "Just Accepted" manuscripts. 


\title{
Electrochemical Stability of Metastable
}

\section{Materials}

\author{
Arunima K. Singh, ${ }^{*}+$ Lan Zhou, Aniketa Shinde, Santosh K. Suram, ${ }^{\ddagger}$ Joseph H. \\ Montoya, "Donald Winston, John M. Gregoire, ${ }^{\ddagger}$ and Kristin A. Persson*,§,\| \\ Joint Center for Artificial Photosynthesis, Lawrence Berkeley National Laboratory, \\ Berkeley, California 94720, U.S.A., Joint Center for Artificial Photosynthesis, California \\ Institute of Technology, Pasadena, CA 91125, USA, Lawrence Berkeley National \\ Laboratory, Berkeley, CA 94720, USA, Environmental Energy Technologies Division, \\ Lawrence Berkeley National Laboratory, Berkeley, CA 94720, USA, and Department of \\ Materials Science and Engineering, University of California, Berkeley, CA 94720, USA \\ E-mail: arunimasingh@lbl.gov; kapersson@lbl.gov
}

\begin{abstract}
We present a first-principles based formalism to provide a quantitative measure of the thermodynamic instability and propensity for electrochemical stabilization, passivation or corrosion of metastable materials in aqueous media. We demonstrate that this

\footnotetext{
${ }^{*}$ To whom correspondence should be addressed

${ }^{\dagger}$ Joint Center for Artificial Photosynthesis, Lawrence Berkeley National Laboratory, Berkeley, California 94720, U.S.A.

${ }_{\ddagger}^{\ddagger}$ Joint Center for Artificial Photosynthesis, California Institute of Technology, Pasadena, CA 91125, USA

"Lawrence Berkeley National Laboratory, Berkeley, CA 94720, USA

$\S$ Environmental Energy Technologies Division, Lawrence Berkeley National Laboratory, Berkeley, CA 94720, USA

"Department of Materials Science and Engineering, University of California, Berkeley, CA 94720, USA 
formalism can assess the relative Gibbs free energy of candidate materials in aqueous media as well as their decomposition products, combining solid and aqueous phases, as a function of $\mathrm{pH}$ and potential. Based on benchmarking against 20 stable as well as metastable materials reported in the literature and also our experimental characterization of metastable triclinic- $\mathrm{FeVO}_{4}$ we present quantitative estimates for the relative Gibbs free energy and corresponding aqueous regimes where these materials are most likely to be stable, form inert passivating films or steadily corrode to aqueous species. Furthermore, we show that the structure and composition of the passivating films formed on triclinic- $\mathrm{FeVO}_{4}$ are also in excellent agreement with the Point Defect Model, as proposed by the corrosion community. An open-source web-app based on the formalism is made available at https://materialsproject.org.

\section{Introduction}

The economic cost of environmental degradation of materials has been estimated to be over 200 billion dollars in the US economy alone. ${ }^{1}$ Corrosion management, improvement in performance and an increased operational life of materials for household appliances, infrastructure, vehicles and manufacturing calls for an improved understanding of materials stability under varying alkalinity, humidity, temperature and pollutant conditions. Further, aqueous media-based electrochemical processes such as water purification and catalysis routinely operate devices at finite potentials and $\mathrm{pH}$ where materials stability is strikingly different from ambient conditions.

A concise equilibrium thermodynamics-based understanding of elemental corrosion in aqueous media can be accurately obtained from the so-called Pourbaix diagrams which indicate the potential and $\mathrm{pH}$ ranges where the different multicomponent oxidation states of materials exist. Marcel Pourbaix and others have collected thermodynamic data for reactions involving metals, their ions, their oxides and occasionally sulphides, providing the

electrochemical phase diagrams for ca. 85 elements in the periodic table. ${ }^{2-4}$ While the elec- 
trochemical stability of elements has been studied extensively, only a small fraction of binary materials and seldom ternary and higher-component materials have been investigated experimentally.

Recently, Persson et al., used first-principles density-functional theory (DFT)-based thermodynamic energies of solids in conjunction with experimentally available ion and aqueous specie energies to predict Pourbaix diagrams of $n$-component materials $(n=1$ to $\infty) .{ }^{5}$ This formalism has reproduced the thermodynamic electrochemical stability of all experimentally investigated $n=1$ systems, and to date, successfully predicted the electrochemical stability of several complex materials such as: $\mathrm{Mn}_{2} \mathrm{~V}_{2} \mathrm{O}_{7},{ }^{6} \mathrm{MnNiO}_{3}, \mathrm{Cu}-\mathrm{V}$-oxides, ${ }^{7}$ and nanoclusters. $^{8}$ In principle, Pourbaix diagrams account for materials only at thermodynamic equilibrium, providing no insight into the electrochemical stability of metastable materials which find practical applications in many commercial applications and research such a steels, ${ }^{9}$ ceramics ${ }^{10}$ photocatalysis ${ }^{11}$ and optoelectronics. ${ }^{12}$ Further, among the 29,902 unique bulk crystalline phases reported in the Inorganic Crystal Structure Database (ICSD), ${ }^{13}$ the firstprinciples-based, zero-temperature Materials Project database computations predict that $50.5 \pm 4 \%(15,097)$ of the experimentally synthesized structures are metastable solid state phases. $^{14}$

We expand the formalism of Persson et al. to enable the evaluation of the relative Gibbs free energy of metastable materials as a function of $\mathrm{pH}$, potential, temperature and concentration of aqueous species. Note that while this formalism accounts for the experimentally measured entropy of several gases, water and all aqueous species, we neglect the entropic contributions for the solids towards Gibbs free energies since the solid-solid entropy differences are likely to be orders of magnitude smaller than the enthalpic contributions at room temperature. ${ }^{15}$ We demonstrate that materials with decomposition Gibbs free energies as high as $0.5 \mathrm{eV} /$ atom have been reported as stable against corrosion due to self-passivation and formation of more stable solid state surface phases. An excellent correlation is found between the Gibbs free energy and propensity of 20 materials (including $\mathrm{GaP}, \mathrm{Zn}\left(\mathrm{FeO}_{2}\right)_{2}$, $\mathrm{Si}$, 
WSe $e_{2}$, GaAs, $\mathrm{Fe}_{2} \mathrm{O}_{3}, \mathrm{WO}_{3}$ and $\mathrm{TiO}_{2}$ ) reported in the experimental literature, to be stable, passivate or corrode. In addition, we grow the metastable triclinic-FeVO ${ }_{4}$ phase and show that the electrochemical response of $\mathrm{FeVO}_{4}$ is in excellent agreement with the computational predictions with respect to both the stability and composition of the self-passivated layers, as applicable. The instability landscape reported in this article provides a critical guide towards environmental degradation management as well as design of metastable materials or protective films in materials of all classes for aqueous media-based applications. Further, we suggest that an a priori knowledge of the passivation layer composition can aid the kinetic and phenomenological Point Defect Model $^{16}$ to predict the microstructure, passivation layer thickness and the kinetic stability of self-passivating films.

The formalism is made available through a user-friendly web-based app which allows for the generation and assessment of the metastability of over 69,000 materials; including estimation of $\mathrm{pH}$, concentration and potential dependent composition of possible passivation layers, available at https://materialsproject.org.

\section{Methods}

Mapping Pourbaix diagrams for multi-component systems requires the knowledge of equilibrium redox reactions as well as the standard state reaction Gibbs free energy of each redox reaction, $\Delta_{r} G^{o}$. For example, a binary $\mathrm{M}-\mathrm{X}$ system in aqueous media can result in a redox reaction such as,

$$
a \mathrm{M}(\mathrm{s})+b \mathrm{X}(\mathrm{s})+c \mathrm{H}_{2} \mathrm{O}(\mathrm{l}) \rightarrow \mathrm{M}_{a} \mathrm{X}_{b} \mathrm{O}_{c} \mathrm{H}_{d}^{m}(\mathrm{aq})+(2 c-d) \mathrm{H}^{+}+(2 c-d+m) \mathrm{e}^{-}
$$

where $a, b, c, d$ are the stoichiometric coefficients of $\mathrm{M}, \mathrm{X}, \mathrm{O}$ and $\mathrm{H}$, respectively, and $m$ is the charge on the aqueous species $\mathrm{M}_{a} \mathrm{X}_{b} \mathrm{O}_{c} \mathrm{H}_{d}^{m}$ which could be positive, negative or zero. The number of competing redox reactions scales rapidly with the number of elements considered to compute the Pourbaix diagram. For instance, for a Fe-V system, there are 11 experimen- 
tally reported Fe-containing and $14 \mathrm{~V}$-containing (positively charged, negatively charged or neutral) aqueous species, along with 14 ground state solids containing one or more of Fe, V or O elements. At equilibrium, the Nernst equation can be used to relate the cell potential, $E^{o}$, to the reaction Gibbs free energy, $\Delta_{r} G$, for each possible redox reaction. For instance,

$$
\begin{aligned}
-\nu F E^{o}=\Delta_{r} G & =\Delta_{r} G^{o}+R T \ln Q \\
& =\Delta_{r} G^{o}+R T \ln \left[\frac{\left(a_{P}\right)^{p} \cdot\left(a_{\mathrm{H}^{+}}\right)^{h}}{\left(a_{R}\right)^{r} \cdot\left(a_{\mathrm{H}_{2} \mathrm{O}}\right)^{w}}\right] \\
& =\Delta_{r} G^{o}+2.303 R T \log \left[\frac{\left(a_{P}\right)^{p}}{\left(a_{R}\right)^{r} \cdot\left(a_{\mathrm{H}_{2} \mathrm{O}}\right)^{w}}\right]-2.303 h R T \mathrm{pH}
\end{aligned}
$$

Where $T$ is the temperature, $F$ is the Faraday constant, $R$ is the ideal gas constant, $\mathrm{pH}=-\log \left(\mathrm{H}^{+}\right), \nu=(2 c-d+m)$ is the number of electrons, $a_{R}^{r}=a_{M(s)}^{a} \cdot a_{X(s)}^{b}$ is the activity of the reactants, $a_{P}^{p}=a_{\mathrm{M}_{a} \mathrm{X}_{b} \mathrm{O}_{c} \mathrm{H}_{d}^{m}}$ is the activity of the products, $a_{\mathrm{H}_{2} \mathrm{O}}^{w}=a_{\mathrm{H}_{2} \mathrm{O}}^{c}$ is the activity of water, and $a_{\mathrm{H}^{+}}^{h}=a_{\mathrm{H}^{+}}^{(2 c-d)}$ is the activity of hydrogen ions for the reaction in Eq. 1. In principle, identifying the redox reaction that minimizes the difference between the contribution from the cell potential and the reaction Gibbs free energy, $\min \left(\Delta_{r} G+\nu F E^{0}\right)$, is sufficient to identify the range of $\mathrm{pH}$ and $E$ where a particular solid or ionic species is stabilized over others for a given temperature, concentration of ions and stiochiometry of elements under consideration.

However, the lack of complete knowledge of possible redox reactions is the limiting factor in this analysis. In previous efforts, computed crystalline solid energies have been combined with experimentally measured free energies of aqueous species, which are readily available in thermodynamic databases. ${ }^{5}$ A thorough description of the scheme of reference energies which allows for the combination of experimental and computational thermodynamic data can be found in Ref. 5. Further, computational materials data is available in larger and more comprehensive quantities than ever before through efforts like The Materials Project, ${ }^{17}$ OQMD ${ }^{18}$ and aflowlib. ${ }^{19}$ The experimentally measured energies of aqueous species, ${ }^{2,3,15,20,21}$ total 362 , corresponding to 80 elements in the periodic table, are also available through the 
Materials Project (MP) API. ${ }^{22}$ Among the 69,640 currently available materials in the MP database, 34,913 materials correspond to compounds in the ICSD, 23,776 are ground states, and the intersection of these sets contains 18,993 compounds. In conjunction with 362 ionic energies for 80 elements in the periodic table, the electrochemical stability for the 23,776 ground state structures can already be determined.

We update the formalism of Persson et al. ${ }^{5}$ to include redox reactions corresponding to an arbitrary metastable material. Metastable materials cannot result in thermodynamically favorable redox reactions, thus, we estimate their Gibbs free energy difference with respect to the Pourbaix stable domains as a function of $\mathrm{pH}$ and $E$, providing electrochemical instability maps for arbitrary metastable materials. This Gibbs free energy difference, $\Delta G_{\mathrm{pbx}}$, thus includes the instabilities arising from the enthalpy difference with respect to the likely decomposition products of the metastable material at zero pressure and zero temperature, also known as energy above the convex hull, $\Delta H_{\text {solid }}$, and contributions from the $\mathrm{pH}$ and voltage factors of Eq. 2. For a detailed information on the mathematical implementation, please refer to the pymatgen python package. ${ }^{23}$

As an example, Figure 1 shows the Pourbaix diagram of the Fe-V-O-H system with a 1:1 composition of $\mathrm{Fe}$ and $\mathrm{V}$ in an infinite reservoir of water. An ionic concentration of $10^{-5} \mathrm{M}$ of both Fe and V species, an activity of solids of 1, temperature of $298 \mathrm{~K}$, and a pressure of $1 \mathrm{~atm}$ is used for the analysis of Fe- $\mathrm{V}-\mathrm{O}-\mathrm{H}$ and all systems described henceforth, unless otherwise noted. The ground state solids relevant to the Fe-V-O-H system, i.e. FeO, $\mathrm{Fe}_{2} \mathrm{O}_{3}, \mathrm{Fe}_{3} \mathrm{O}_{4}$, $\mathrm{Fe}_{2} \mathrm{~V}_{4} \mathrm{O}_{13}, \mathrm{Fe}_{3} \mathrm{~V}, \mathrm{FeV}, \mathrm{VO}_{2}, \mathrm{~V}_{2} \mathrm{O}_{3}, \mathrm{~V}_{3} \mathrm{O}_{4}$ and $\mathrm{V}_{2} \mathrm{O}_{5}$, are mapped in the Pourbaix diagram, and their stability regions can be identified through inspection of the figure. However, the metastable triclinic phase of $\mathrm{FeVO}_{4}$ is not visibly represented in the equilibrium Pourbaix diagram. Under ambient pressure, this phase exhibits a $\Delta H_{\text {solid }}=0.34 \mathrm{eV} /$ atom for a $1: 1$ spontaneous decomposition to the stable $\mathrm{Fe}_{2} \mathrm{O}_{3}$ and $\mathrm{Fe}_{2} \mathrm{~V}_{4} \mathrm{O}_{13}$ solids. The $\Delta G_{\mathrm{pbx}}$ with respect to the Pourbaix stable domains, superimposed on the Pourbaix diagram, enables estimation of the instability of $\mathrm{FeVO}_{4}$ against all possible combinations of solid as well as aqueous 


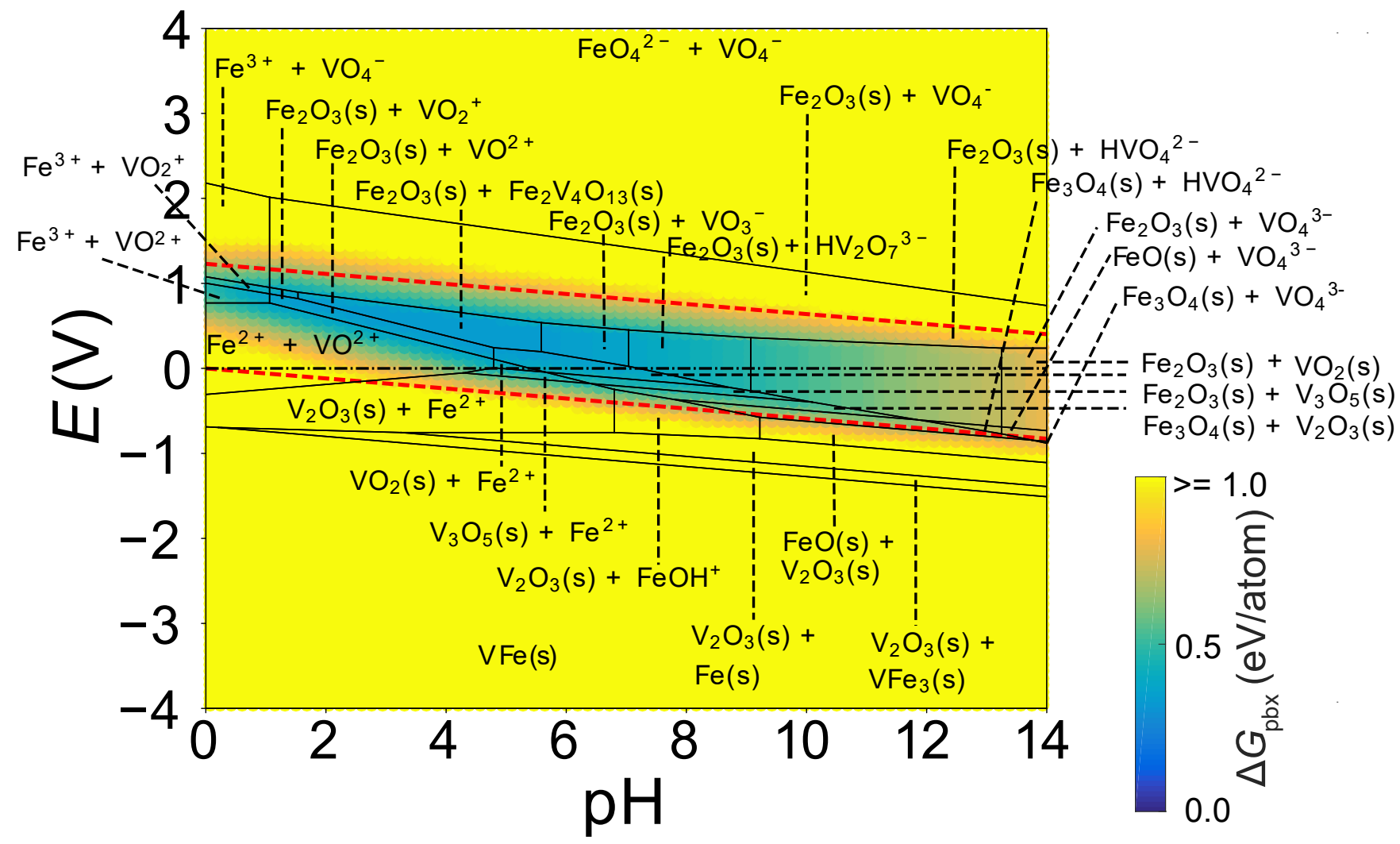

Figure 1: (Color online) Computationally predicted Pourbaix diagram of the Fe-V-O-H system. The Gibbs free energy, $\Delta G_{\mathrm{pbx}}$, of the metastable triclinic-FeVO $\mathrm{F}_{4}$ phase with respect to the Pourbaix stable phases is superimposed and represented by the colorbar. The lowest value of $\Delta G_{\mathrm{pbx}}$ for $\mathrm{FeVO}_{4}$ is $0.34 \mathrm{eV} /$ atom at $\mathrm{pH}=1.63$ and voltage of $E=0.85 \mathrm{~V}$, where it is predicted to phase transform to $\mathrm{Fe}_{2} \mathrm{~V}_{4} \mathrm{O}_{13}$ and $\mathrm{Fe}_{2} \mathrm{O}_{3}$, a solid state reaction enabled by the stability of both reaction products under this electrochemical condition. The red dashed lines denote potentials of $0 \mathrm{~V}$ vs RHE and $1.23 \mathrm{~V}$ vs RHE. 
species. We note that the most favorable $\Delta G_{\mathrm{pbx}}$ for $\mathrm{FeVO}_{4}$ occurs where it is expected to decompose into $\mathrm{Fe}_{2} \mathrm{~V}_{4} \mathrm{O}_{13}$ and $\mathrm{Fe}_{2} \mathrm{O}_{3}$ in equal amounts to maintain the 1:1 stoichiometry of Fe and $\mathrm{V}$. The minimum of the $\Delta G_{\mathrm{pbx}}=0.34 \mathrm{eV} /$ atom is found at $\mathrm{pH}=1.63$ and $E=1.85$ $\mathrm{V}$, which includes the $\Delta H_{\text {solid }}$ and no contributions from the potential and $\mathrm{pH}$ factors are expected based on the redox reactions. The $\Delta G_{\mathrm{pbx}}$ increases rapidly beyond the stability domain of $\mathrm{Fe}_{2} \mathrm{~V}_{4} \mathrm{O}_{13}$ and $\mathrm{Fe}_{2} \mathrm{O}_{3}$ indicating that it is progressively likely that the Pourbaixdetermined phases will be more favorable than the metastable $\mathrm{FeVO}_{4}$. Similar plots were created for all the materials studied in this work.

In order to assess the $\Delta G_{\mathrm{pbx}}$ which can be tolerated due to high barriers for solid-solid phase transformations or mitigated by dissolution-precipitation-assisted surface passivation, we compare the predicted $\Delta G_{\mathrm{pbx}}$ with the electrochemical behavior of materials reported in the experimental literature. In the next section we show examples of materials with $\Delta G_{\mathrm{pbx}}$ up to $0.5 \mathrm{eV} /$ atom have been experimentally reported as stable within some observation time. While the thermodynamic driving force for dissolution is an important metric, we find that it is equally important to consider the nature of the decomposition products, e.g. whether they form aqueous ions, solid phases or a combination thereof. For materials where $\Delta G_{\mathrm{pbx}}>0$ and self-passivating layers form on the surface of the materials, we show that the predicted passivation layer compositions are in agreement with experimentally observed passivation layer compositions.

Methods for the model validation experiments are described in the Supporting Information.

\section{Results and Discussion}

\section{Validation Against Experimental Reports in the Literature}

Figure 2 shows the theoretically computed $\Delta G_{\mathrm{pbx}}$ for over 20 well known photoanode materials. We choose photoanode materials for a comparison of the theoretical predictions with 
experimental reports in the literature since numerous studies report the electrochemical stability of photoanode materials. After the discovery of the first photoanode material in 1972, $\mathrm{TiO}_{2},{ }^{24}$ over 130 semiconductors, including oxides, sulphides and phosphides, ${ }^{11}$ have been extensively studied to improve, among other properties, their aqueous stability and operational life. The $\Delta G_{\mathrm{pbx}}$ is computed for a potential of $1.5 \mathrm{~V}$ vs RHE (which accounts for the $1.23 \mathrm{eV}$ free energy of water splitting and an overpotential of $0.27 \mathrm{eV}$ that is typically required for electrocatalysis) and $\mathrm{pH}$ values corresponding to the experimental measurements in the literature, Table 1.

The 12 metastable materials, anatase $-\mathrm{TiO}_{2}, \alpha-\mathrm{Cu}_{2} \mathrm{~V}_{2} \mathrm{O}_{7}, \alpha-\mathrm{CuV}_{2} \mathrm{O}_{6}, \mathrm{BiVO}_{4}, \gamma-\mathrm{Cu}_{3} \mathrm{~V}_{2} \mathrm{O}_{8}$, $\mathrm{BiFeO}_{3}, \mathrm{Fe}_{2} \mathrm{TiO}_{5}, \alpha-\mathrm{Cu}_{3} \mathrm{~V}_{2} \mathrm{O}_{8}, \mathrm{Cu}_{11} \mathrm{~V}_{6} \mathrm{O}_{26}, \mathrm{CuWO}_{4}, \mathrm{FeV}_{2} \mathrm{O}_{4}$ and $\mathrm{FeVO}_{4}$ have $\Delta H_{\text {solid }}$ ranging from $0.01 \mathrm{eV} /$ atom, for anatase $-\mathrm{TiO}_{2}$, to $0.11 \mathrm{eV} /$ atom, for $\mathrm{FeVO}_{4}$. The remaining 13 materials, $\mathrm{Zn}\left(\mathrm{FeO}_{2}\right)_{2}, \mathrm{Bi}_{2} \mathrm{MoO}_{6}, \mathrm{WO}_{3}, \mathrm{Fe}_{2} \mathrm{O}_{3}, \mathrm{Bi}_{2} \mathrm{WO}_{6}, \mathrm{Fe}_{2} \mathrm{~V}_{4} \mathrm{O}_{13}, \beta-\mathrm{Cu}_{2} \mathrm{~V}_{2} \mathrm{O}_{7}, \mathrm{WSe}_{2}$, $\mathrm{CdS}$, GaAs, InP, GaP and Si are thermodynamically stable materials, i.e. their $\Delta H_{\text {solid }}=0$ $\mathrm{eV} /$ atom.

Evidently, the $\Delta G_{\mathrm{pbx}}$ should be zero for the electrochemically stable compounds. However, somewhat surprisingly, excluding the spinel $\mathrm{ZnFe}_{2} \mathrm{O}_{4}$ and the orthorhombic $\mathrm{WO}_{3}$, all the materials which are found to be stable experimentally have a $\Delta G_{\mathrm{pbx}}>0$, up to 0.5 $\mathrm{eV} /$ atom. Our calculations predict that $\mathrm{WO}_{3}$ has a $\Delta G_{\mathrm{pbx}}=0$ for $\mathrm{pH}<4$ solutions and it has also been reported to be stable experimentally at $\mathrm{pH}<4, .{ }^{25,26}$ Further, at higher $\mathrm{pH}$ values it has been observed to corrode, which is in agreement with the prediction that the orthorhombic $\mathrm{WO}_{3}$ should dissolve as $\mathrm{WO}_{4}^{-}$ions with $\Delta G_{\mathrm{pbx}}$ of up to $1 \mathrm{eV} /$ atom. The spinel structure of $\mathrm{ZnFe}_{2} \mathrm{O}_{4}$ has $\Delta G_{\mathrm{pbx}}=0 \mathrm{eV} /$ atom over a large alkaline range, $\mathrm{pH}=7$-14, however, no experimental reports of the electrochemical stability could be identified in the literature. ${ }^{27,28}$ For further details, see Figure S1 in the supporting information for pH dependent $\Delta G_{\mathrm{pbx}}$ and decomposition products of all the materials at $1.5 \mathrm{~V}$ (all voltages here on are $v s \mathrm{RHE})$.

Amongst those materials which exhibit a $\Delta G_{\mathrm{pbx}}>0$ but are still found to be stable 


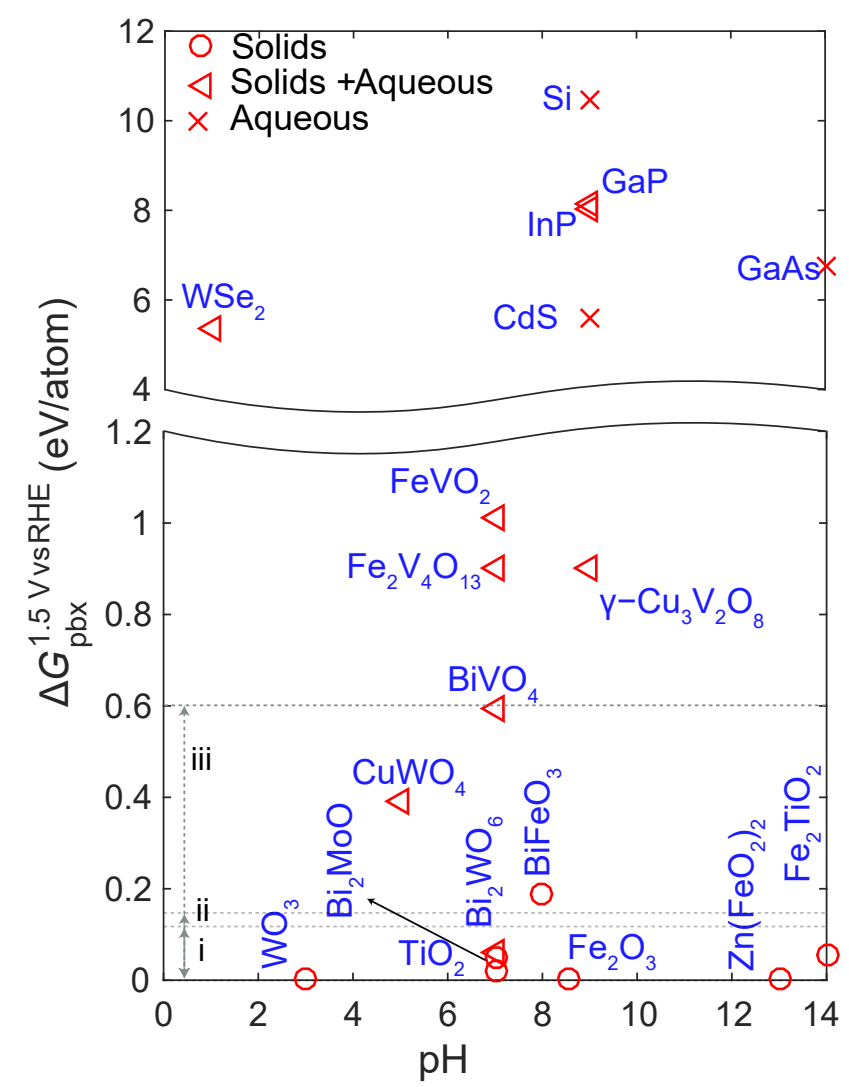

Figure 2: (Color online) The $\Delta G_{\mathrm{pbx}}$ of photoanode materials at $1.5 \mathrm{~V}$ vs RHE at pH values corresponding to those in experimental reports, listed in Table 1. Materials which are expected to remain stable or decompose to only solid species are shown as circles. Those which decompose to solids as well as aqueous species are shown as triangles and the ones which are expected to dissociate to only aqueous species are shown as cross symbols. Refer Table 1 for details of the decomposed species. The driving forces to stabilize materials with energies marked in region (i) can be due to ionic concentration fluctuations, those marked in region (ii) could be due to temperature fluctuations and those by region (iii) due to activation energy barriers. Further, operational stability can also be obtained due to formation of inert passivation layers. 
experimentally, $\mathrm{Fe}_{2} \mathrm{O}_{3}$ exhibits a $\Delta G_{\mathrm{pbx}}=0.001 \mathrm{eV} /$ atom at $\mathrm{pH} 2-12$ which is within the numerical accuracy of DFT. Experimental measurements are in excellent agreement showing that $\mathrm{Fe}_{2} \mathrm{O}_{3}$ indeed exhibits a large $\mathrm{pH}$ stability window from 2-14. ${ }^{29}$ The widely used photoanode, anatase $-\mathrm{TiO}_{2}$, also has a small $\Delta G_{\mathrm{pbx}}=0.02 \mathrm{eV} /$ atom against the formation of its polymorph $\alpha-\mathrm{TiO}_{2}$. This small $\Delta G_{\mathrm{pbx}}$ is found to be insufficient to drive a solid-solid phase transformation and hence anatase $-\mathrm{TiO}_{2}$ is found to be extremely robust in both alkaline and acidic regions, $\mathrm{pH}=0-14 .{ }^{30,31} \mathrm{Bi}_{2} \mathrm{MoO}_{6}$ has a slightly larger $\Delta G_{\mathrm{pbx}}=0.05 \mathrm{eV} /$ atom and is predicted to dissociate to $\mathrm{Bi}_{4} \mathrm{O}_{7}$ and $\mathrm{MoO}_{4}{ }^{-}$at $\mathrm{pH}=7$ and $1.4 \mathrm{~V}$, but is found to be stable experimentally. ${ }^{32}$ At $\mathrm{pH}=7, \mathrm{Bi}_{2} \mathrm{WO}_{6}$ has a $\Delta G_{\mathrm{pbx}}=0.06 \mathrm{eV} /$ atom, comparable to that of $\mathrm{Bi}_{2} \mathrm{MoO}_{6}$. Our formalism predicts a thermodynamic liability to dissociate to $\mathrm{Bi}_{2} \mathrm{O}_{4}$ and $\mathrm{WO}_{4}{ }^{2-}$ under these conditions. Yet, experimentally it has been observed to exhibit no significant drop in photocurrent and no obvious change in the morphology. ${ }^{33}$ Another material which remains stable despite a $\Delta G_{\mathrm{pbx}}>0$ is $\mathrm{FeBiO}_{3}$, which at $\mathrm{pH}=7.5$ and $1.7 \mathrm{~V}$ is found to be operationally stable despite the predicted dissociation into $\mathrm{Fe}_{2} \mathrm{O}_{3}$ and $\mathrm{Bi}_{4} \mathrm{O}_{7}^{-34,35}$ as expected from our thermodynamic predictions. The most extreme of these examples is the monoclinic scheelite $\mathrm{BiVO}_{4}$ which has attracted recent interest due to conflicting reports of aqueous stability. The material was deemed stable ${ }^{36}$ at $\mathrm{pH}=7$ which corresponds to a very large $\Delta G_{\mathrm{pbx}}=0.59$. Similarly, at $\mathrm{pH}=6.6, E=1.41 \mathrm{~V}$, where $\Delta G_{\mathrm{pbx}}=0.45 \mathrm{eV} /$ atom, no change in the X-ray diffraction (XRD) pattern or optical absorbance of $\mathrm{BiVO}_{4}$ was observed. ${ }^{37}$ On the other hand, recent combined experimental and computational work shows that $\mathrm{BiVO}_{4}$ corrodes in alkaline $\mathrm{pH}$ at $1.23 \mathrm{~V} .{ }^{38}$

In contrast, materials with $\Delta G_{\mathrm{pbx}}>5.5 \mathrm{eV} /$ atom, i.e. Si, GaAs, InP, CdS and InP, corrode vigorously. ${ }^{49-52}$ We note that these five materials are predicted to either decompose to only aqueous or a combination of oxides and aqueous species. None of them exhibit instability to only solid phases. Consequently, these materials are coated with more stable materials such as $\mathrm{TiO}_{2}$ and $\mathrm{Fe}_{2} \mathrm{O}_{3}{ }^{31,53}$ when used as photoanodes.

All other examined materials are found to self-passivate with passivation layers whose 
Table 1: The predicted stable species in aqueous media, Decomposed Species, and $\Delta G_{\mathrm{pbx}}$, in $\mathrm{eV} /$ atom, of 25 materials in water at $1.5 \mathrm{~V}$ vs $\mathrm{RHE}$. The $\mathrm{pH}$ values, $\mathrm{pH}_{\mathrm{Exp}}$, correspond to the $\mathrm{pH}$ values in the measurements carried out in the listed references. The Materials Project material ids (mp-id) corresponding to the materials are listed as well.

\begin{tabular}{|c|c|c|c|c|c|}
\hline Material & $\Delta G_{\mathrm{pbx}}$ & $\mathrm{pH}_{\mathrm{Exp}}$ & Decomposed Species & mp-id & Ref. \\
\hline $\mathrm{Zn}\left(\mathrm{FeO}_{2}\right)_{2}$ & 0.00 & 13 & $\mathrm{Zn}\left(\mathrm{FeO}_{2}\right)_{2}(\mathrm{~s})$ & mp-19313 & 27,28 \\
\hline $\mathrm{WO}_{3}$ & 0.00 & 3 & $\mathrm{WO}_{3}(\mathrm{~s})$ & mp-19342 & 25 \\
\hline $\mathrm{Fe}_{2} \mathrm{O}_{3}$ & 0.00 & 9 & $\mathrm{Fe}_{2} \mathrm{O}_{3}(\mathrm{~s})$ & mp-24972 & 29,31 \\
\hline $\mathrm{TiO}_{2}$ & 0.02 & 7 & $\mathrm{TiO}_{2}(\mathrm{~s})$ & mp-390 & 30,31 \\
\hline $\mathrm{Bi}_{2} \mathrm{MoO}_{6}$ & 0.05 & 7 & $\mathrm{Bi}_{2} \mathrm{MoO}_{6}(\mathrm{~s})$ & mp-25708 & 32 \\
\hline $\mathrm{Fe}_{2} \mathrm{TiO}_{5}$ & 0.06 & 14 & $\mathrm{Fe}_{2} \mathrm{O}_{3}(\mathrm{~s})+\mathrm{TiO}_{2}(\mathrm{~s})$ & mp-24977 & 39 \\
\hline $\mathrm{Bi}_{2} \mathrm{WO}_{6}$ & 0.06 & 7 & $\mathrm{Bi}_{4} \mathrm{O}_{7}(\mathrm{~s})+\mathrm{WO}_{4}^{2-}$ & mp-25730 & 33 \\
\hline $\mathrm{BiFeO}_{3}$ & 0.19 & 8 & $\mathrm{Fe}_{2} \mathrm{O}_{3}(\mathrm{~s})+\mathrm{Bi}_{4} \mathrm{O}_{7}(\mathrm{~s})$ & mp-24932 & 34,35 \\
\hline $\mathrm{CuWO}_{4}$ & 0.39 & 5 & $\mathrm{Cu}_{2} \mathrm{O}_{3}(\mathrm{~s})+\mathrm{WO}_{4}^{2-}$ & mp-510632 & 26,40 \\
\hline $\mathrm{BiVO}_{4}$ & 0.59 & 7 & $\mathrm{Bi}_{4} \mathrm{O}_{7}(\mathrm{~s})+\mathrm{VO}_{4}^{-}$ & mp-504878 & $36-38$ \\
\hline $\mathrm{Cu}_{11} \mathrm{~V}_{6} \mathrm{O}_{26}$ & 0.87 & 9 & $\mathrm{Cu}_{2} \mathrm{O}_{3}(\mathrm{~s})+\mathrm{VO}_{4}^{-}$ & mp-505456 & 7,41 \\
\hline $\mathrm{Fe}_{2} \mathrm{~V}_{4} \mathrm{O}_{13}$ & 0.90 & 7 & $\mathrm{Fe}_{2} \mathrm{O}_{3}(\mathrm{~s})+\mathrm{VO}_{4}^{-}$ & mp-565529 & 42 \\
\hline$\gamma-\mathrm{Cu}_{3} \mathrm{~V}_{2} \mathrm{O}_{8}$ & 0.90 & 9 & $\mathrm{Cu}_{2} \mathrm{O}_{3}(\mathrm{~s})+\mathrm{VO}_{4}^{-}$ & mp-504747 & $7,41,43$ \\
\hline$\alpha-\mathrm{Cu}_{3} \mathrm{~V}_{2} \mathrm{O}_{8}$ & 0.92 & 9 & $\mathrm{Cu}_{2} \mathrm{O}_{3}(\mathrm{~s})+\mathrm{VO}_{4}^{-}$ & mp-600273 & 7,41 \\
\hline$\beta-\mathrm{Cu}_{2} \mathrm{~V}_{2} \mathrm{O}_{7}$ & 1.00 & 9 & $\mathrm{Cu}_{2} \mathrm{O}_{3}(\mathrm{~s})+\mathrm{VO}_{4}^{-}$ & mp-559660 & 7,44 \\
\hline $\mathrm{FeVO}_{4}$ & 1.01 & 7 & $\mathrm{Fe}_{2} \mathrm{O}_{3}(\mathrm{~s})+\mathrm{VO}_{4}^{-}$ & mp-540630 & 45,46 \\
\hline$\alpha-\mathrm{Cu}_{2} \mathrm{~V}_{2} \mathrm{O}_{7}$ & 1.02 & 9 & $\mathrm{Cu}_{2} \mathrm{O}_{3}(\mathrm{~s})+\mathrm{VO}_{4}^{-}$ & mp-505508 & 7,44 \\
\hline$\alpha-\mathrm{CuV}_{2} \mathrm{O}_{6}$ & 1.28 & 9 & $\mathrm{Cu}_{2} \mathrm{O}_{3}(\mathrm{~s})+\mathrm{VO}_{4}^{-}$ & mp-741706 & 7,47 \\
\hline $\mathrm{FeV}_{2} \mathrm{O}_{4}$ & 3.10 & 7 & $\mathrm{Fe}_{2} \mathrm{O}_{3}(\mathrm{~s})+\mathrm{VO}_{4}^{-}$ & mp-510496 & 45 \\
\hline $\mathrm{WSe}_{2}$ & 5.38 & 1 & $\mathrm{WO}_{3}(\mathrm{~s})+\mathrm{HSeO}_{4}^{-}$ & mp-1821 & 48 \\
\hline $\mathrm{CdS}$ & 5.58 & 9 & $\mathrm{Cd}^{2+}+\mathrm{SO}_{4}^{2-}$ & mp-672 & 49,50 \\
\hline GaAs & 6.77 & 14 & $\mathrm{AsO}_{4}^{3-}+\mathrm{GaO}_{3}^{3-}$ & mp-2534 & $25,31,51,52$ \\
\hline $\mathrm{InP}$ & 8.01 & 9 & $\mathrm{In}_{2} \mathrm{O}_{3}(\mathrm{~s})+\mathrm{HPO}_{4}{ }^{2-}$ & mp-20351 & 25,53 \\
\hline $\mathrm{GaP}$ & 8.15 & 9 & $\mathrm{Ga}_{2} \mathrm{O}_{3}(\mathrm{~s})+\mathrm{HPO}_{4}{ }^{2-}$ & mp-2490 & 25,31 \\
\hline $\mathrm{Si}$ & 10.45 & 9 & $\mathrm{H}_{4} \mathrm{SiO}_{4}(\mathrm{aq})$ & mp-149 & 25,31 \\
\hline
\end{tabular}


compositions are in excellent agreement with those predicted theoretically. For instance, $\mathrm{WSe}_{2}$ is predicted to dissociate to $\mathrm{WO}_{3}$ and solvated Se atoms as $\mathrm{HSeO}_{4}^{-}$ions with a $\Delta G_{\mathrm{pbx}}$ $=4.96 \mathrm{eV} /$ atom at $\mathrm{pH}=1$ and $E=1.43 \mathrm{~V}$, in excellent agreement with the experimental observation that in perchloric acid, $\mathrm{pH}=0.4-1.0$, and at $1.43 \mathrm{VWSe}_{2}$ forms a thin porous $\mathrm{WO}_{3}$ passivation layer. ${ }^{48}$ In another case, it is observed experimentally that mesoporous films of $\mathrm{Fe}_{2} \mathrm{TiO}_{5}$ form self-passivating films composed of a mixture of mesoporous $\mathrm{Fe}_{2} \mathrm{TiO}_{5}$, $\mathrm{Fe}_{2} \mathrm{O}_{3}$ and $\mathrm{Fe}$-doped anatase- $\mathrm{TiO}_{2}{ }^{39}$ at $\mathrm{pH}=13.9$. Even though a direct comparison cannot be made between the experiments for the mesoporous $\mathrm{Fe}_{2} \mathrm{TiO}_{5}$ and our calculations for crystalline $\mathrm{Fe}_{2} \mathrm{TiO}_{5}$, we predict that crystalline $\mathrm{Fe}_{2} \mathrm{TiO}_{5}$ should indeed decompose to $\mathrm{Fe}_{2} \mathrm{O}_{3}$ and $\mathrm{TiO}_{2}$ with a $\Delta G_{\mathrm{pbx}}=0.06 \mathrm{eV} /$ atom. Another class of materials, copper-vanadates, are shown to form self-passivating layers in the alkaline region ${ }^{7,41,44}$ at $\mathrm{pH}=7-13$. This is in agreement with the large $\Delta G_{\mathrm{pbx}}$ of the $\mathrm{Cu}$-vanadates, exceeding $1 \mathrm{eV} /$ atom, and a prediction that they dissociate to $\mathrm{Cu}_{2} \mathrm{O}_{3}$ and $\mathrm{VO}_{4}{ }^{-}$ions in aqueous solution.

Several other experimental reports provide an indirect evidence for the formation of selfpassivation layers. For example, $\mathrm{FeV}_{2} \mathrm{O}_{4}$ at $\mathrm{pH}=7$ is found to remain almost stable with about $20 \%$ change in current density at $1.0 \mathrm{~V} .{ }^{45}$ It is likely that the reduction in the current density could be due to the formation of $\mathrm{Fe}_{2} \mathrm{O}_{3}$ passivation layers when $\mathrm{V}$ dissolves as $\mathrm{VO}_{4}^{-}$. However, photodegradation and formation of solid electrolyte deposits could also be a cause of the decrease in $\mathrm{FeV}_{2} \mathrm{O}_{4}$ film's current density. Similar Gibbs free energy based metric was used to predict the aqueous stability of Li- and Na-based materials which are used as solid electrolytes. ${ }^{54}$ However, stability and passivation film composition were not verified due to limited experimental literature.

Hence, we surmise that materials with $\Delta G_{\mathrm{pbx}}$ up to high values of as much as 0.5 $\mathrm{eV} /$ atom can persist in electrochemical environments due to two possible reasons. Firstly, the energy gained via dissociation to the Pourbaix stable domains may not be sufficient to overcome the energy barrier for the dissociation reactions. Energy barriers for bulk solid state transformations are found to be well below $1 \mathrm{eV} /$ atom, greatly depending on the system under 
consideration. ${ }^{55-58}$ Secondly, if the decomposition products include a major contribution from solid state phase(s), preferential dissolution of some species can enable formation of a selfpassivating interphase, which will protect the underlying material. Furthermore, we note that fluctuations in the ionic concentration and temperature can contribute significantly to the corrosion/passivation process. For example, two orders of magnitude increase in the ionic concentration can result in up to $2 \times 2.303 \times R T / F(0.118 \mathrm{eV} /$ atom for $T=298$ $\mathrm{K}$ or $0.128 \mathrm{eV} /$ atom for $T=323 \mathrm{~K}$ ) reduction in the decomposition energy. Considering possible selective thermodynamic dissolution and precipitation of different species it is likely that materials be immune to corrosion by self-passivation at $\Delta G_{\mathrm{pbx}}$ energies which are of the order of a fraction of an $\mathrm{eV} /$ atom. Needless to say the maximum $\Delta G_{\mathrm{pbx}}$ up to which a material is stable is very much dependent on the system and small changes in the ionic concentration or small adjustments in $\mathrm{pH}$ and potential can be helpful in stabilizing materials.

While crystalline materials were used as inputs for the theoretical analysis, the experimental reports of the 20 materials encompassed crystalline, amorphous and porous phases synthesized under different conditions. These materials comprise different chemistries: oxides, phosphides, sulphides, selenides and arsenides; and were investigated under different electrolytes and electrolyte concentrations. In addition, while the photoanode surfaces were characterized carefully in some reports, the stability and surface composition of several photoanodes were more indirect.

\section{Experimental Validation for Triclinic-FeVO 4}

As further validation of our methodology and to explore the importance of our identification and classification of decomposition products, we perform experiments based on the calculations of Fig. 1. A thin film of the metastable triclinic- $\mathrm{FeVO}_{4}$, which has $\Delta H_{\text {solid }}=0.11$ $\mathrm{eV}$ /atom, was grown via sputtering (see SI). We studied the elemental etch rates and surface compositions before and after the electrochemical reactions at various voltages in an acidic solution of $\mathrm{pH}=2.9$ and compared them to our calculations. 
Table 2 shows the electrochemical response of $\mathrm{FeVO}_{4}$ at this $\mathrm{pH}$ for various voltages as expected from our calculations. At voltages of -0.4 and $0.0 \mathrm{~V} \mathrm{FeVO}_{4}$ is expected to form a coating of bixbyite-type $\mathrm{V}_{2} \mathrm{O}_{3}$ concurrently loosing $\mathrm{Fe}$ as $\mathrm{Fe}^{2+}$ ions. At the voltage of $0.4 \mathrm{~V}$ our calculations predict it to corrode into primarily $\mathrm{Fe}^{2+}$ and $\mathrm{VO}^{2+}$ ions. At a higher voltage of $0.8 \mathrm{~V}$ it is predicted to phase transform into monoclinic $\mathrm{Fe}_{2} \mathrm{~V}_{4} \mathrm{O}_{13}$ and $\alpha-\mathrm{Fe}_{2} \mathrm{O}_{3}$. Finally, at $1.2 \mathrm{~V}$ and $1.6 \mathrm{~V}$ a coating of $\alpha-\mathrm{Fe}_{2} \mathrm{O}_{3}$ is expected with loss of $\mathrm{V}$ as $\mathrm{VO}^{4-}$ ions.

Table 2: The predicted stable species in aqueous media, Decomposed Species, and $\Delta G_{\mathrm{pbx}}$ of the triclinic- $\mathrm{FeVO}_{4}$ in water at a $\mathrm{pH}$ of 2.9 and potentials, $E$, ranging from $-0.4 \mathrm{~V}$ to $1.6 \mathrm{~V}$ vs RHE.

\begin{tabular}{lll}
\hline$E$ vs RHE & $\Delta G_{\mathrm{pbx}} \mathrm{eV} /$ atom & Decomposed Species \\
\hline-0.4 & 1.64 & $\mathrm{~V}_{2} \mathrm{O}_{3}(\mathrm{~s})+\mathrm{Fe}^{2+}$ \\
0.0 & 1.04 & $\mathrm{~V}_{2} \mathrm{O}_{3}(\mathrm{~s})+\mathrm{Fe}^{2+}$ \\
0.4 & 0.62 & $\mathrm{Fe}^{2+}+\mathrm{VO}^{2+}$ \\
0.8 & 0.34 & $\mathrm{Fe}_{2} \mathrm{~V}_{4} \mathrm{O}_{13}(\mathrm{~s})+\mathrm{Fe}_{2} \mathrm{O}_{3}(\mathrm{~s})$ \\
1.2 & 0.59 & $\mathrm{Fe}_{2} \mathrm{O}_{3}(\mathrm{~s})+\mathrm{VO}^{4-}$ \\
1.6 & 0.99 & $\mathrm{Fe}_{2} \mathrm{O}_{3}(\mathrm{~s})+\mathrm{VO}^{4-}$ \\
\hline
\end{tabular}

A thin film composition library of $\mathrm{Fe}_{1-\mathrm{x}} \mathrm{V}_{\mathrm{x}} \mathrm{O}_{\mathrm{z}}$ was synthesized by combinatorial sputtering of Fe and V metal targets on fluorine doped tin oxide (FTO) coated glass substrate. The $\mathrm{FeVO}_{4}$ phase pure regions in this composition library were determined using XRD. As expected, X-ray photoelectron spectroscopy (XPS, performed after air exposure) revealed the presence of $\mathrm{Fe}^{3+}$ and $\mathrm{V}^{+5}$ in these samples in approximately equal amounts (see Figure S3). In order to assess the electrochemical stability of these phase pure $\mathrm{FeVO}_{4}$ samples, six as-deposited samples were polarized at $-0.4,0.0,0.4,0.8,1.2$, and $1.6 \mathrm{~V}$ respectively in an aqueous electrolyte solution buffered at $\mathrm{pH} 2.9$ (0.1 M potassium phosphate, $0.04 \mathrm{M}$ phosphoric acid with $0.25 \mathrm{M}$ sodium sulfate) for 15 mins. In order to maintain a low ionic concentration in the solution over the course of this electrochemical process, it was performed in a scanning droplet cell with a rapid solution flow (approximately $0.5 \mathrm{~L} \mathrm{~cm}^{-2} \mathrm{~s}^{-1}$ ) over the working electrode. XRD-determined phases, the X-ray fluorescence(XRF)-determined molar concentrations of Fe and V and the XPS determined surface compositions were measured both before and after exposure to the aqueous electrochemical environment. 
As the entire film thickness is within the sampling depth of XRF, comparison of the pre- and post-electrochemisty Fe and V molar concentrations provides an estimate of the average elemental etching rate during the experiments. Two example XRF spectra of films pre- and post-electrochemistry at potentials of $0.4 \mathrm{~V}$ and $0.8 \mathrm{~V}$ are shown in Figure $3(\mathrm{a})$ and (b), respectively. The V K- $\alpha$ and Fe K- $\alpha$ peaks were used for quantification of elemental concentrations and ultimately the average etch rates shown in Figure 4(a). At $0.4 \mathrm{~V}$, about $50 \%$ drop in the intensities of these peaks indicates that approximately half of the $\mathrm{FeVO}_{4}$ film corroded away during the 15 minute experiment, which is also supported by the XRD characterization of the sample, see Figure S2, which shows the same $\mathrm{FeVO}_{4}$ pattern but with approximately half the intensity in the post-electrochemistry measurement compared to the as-prepared measurement. The XPS signal from this sample (Figure S3) shows a peak corresponding to Sn from the FTO conducting layer, indicating that some regions of the thin film dissolved completely.

No change in $\mathrm{FeVO}_{4}$ was observed in XRD characterization of the samples held at other potentials (Figure S2). However, the post-electrochemistry measurements included a signal from the electrolyte salt, indicating that upon drying the samples, some electrolyte salts precipitated on each sample's surface. As a result, Na, S and P were detected in the postelectrochemistry XRF signals, Figure 3. To understand the effect of the salt coating on the XRF measurement, we inspect the Si and Fe signals from the substrate and Sn signal from the FTO layer, whose slightly lowered intensity in the post-electrochemistry measurement demonstrates that the salt coating attenuates the XRF signal, resulting in a small apparent corrosion rate for both Fe and V even in the absence of corrosion. Consequently, Figure 4(a) provides an upper bound for the elemental etch rate of $\mathrm{FeVO}_{4}$.

Only the $0.4 \mathrm{~V}$ sample exhibited substantial corrosion, which is consistent with the theoretical prediction that all decomposition products are solution-phase species at that condition. At all the remaining potentials, the elemental etch rates are nearly zero, in agreement with the theoretical results which predict that self-passivating coatings should be formed 
(a)

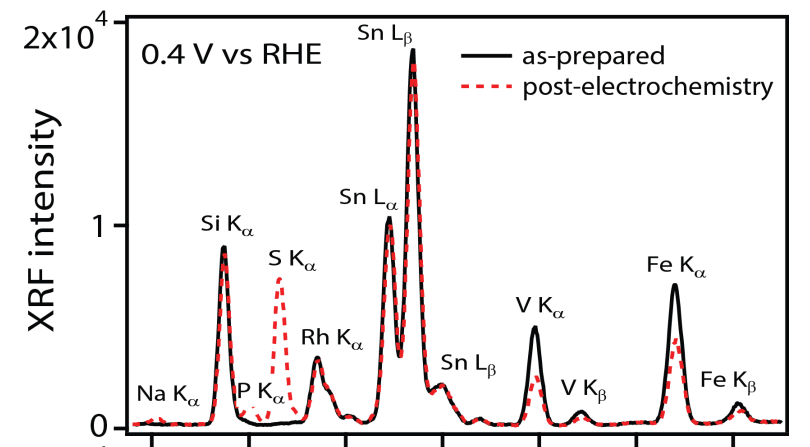

(b)

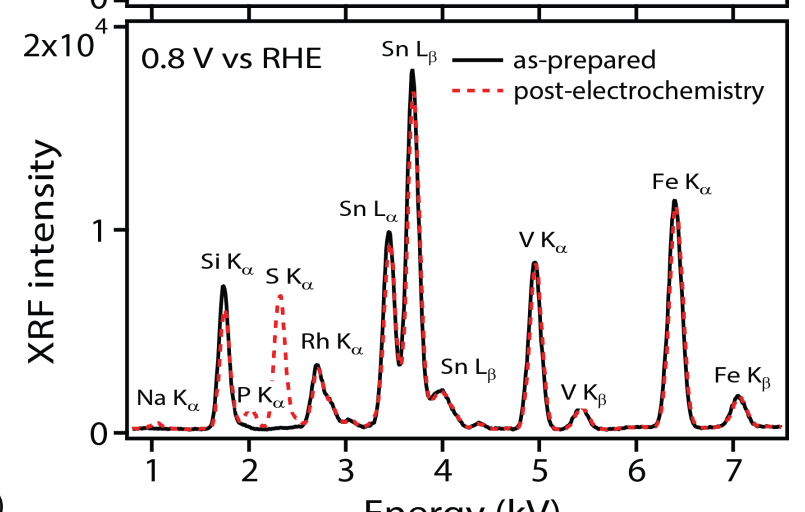

Figure 3: (Color online) XRF spectra for $\mathrm{FeVO}_{4}$ sample before and after 15 mins electrochemical stability measurement in $\mathrm{pH} 2.9$ under the potential of (a) $0.4 \mathrm{~V}$ and (b) $0.8 \mathrm{~V}$ vs RHE.

on the surface of $\mathrm{FeVO}_{4}$. At $0.8 \mathrm{~V}$, the XRD signal shows (see Figure $\mathrm{S} 2$ ) that the $\mathrm{FeVO}_{4}$ crystal structure was unchanged, indicating that the $\mathrm{FeVO}_{4}$ most likely did not transform to the predicted solid products $\left(\mathrm{Fe}_{2} \mathrm{~V}_{4} \mathrm{O}_{13}\right.$ and $\left.\mathrm{Fe}_{2} \mathrm{O}_{3}\right)$. This could possibly be due to the relatively low driving force $\left(\Delta G_{\mathrm{pbx}}=0.336 \mathrm{eV} /\right.$ atom $)$ for such a large solid-solid structural reorganization and no assistance from selective dissolution-preciptation processes as both Fe and $\mathrm{V}$ are predicted as stable against dissolution under these conditions.

The electrolyte salt coating on the electrochemically processed films resulted in relatively low Fe and V signals in the XPS spectra.The Fe $2 p$ and V $2 p$ XPS signals were compared with literature spectra for various species, indicating that the $\mathrm{Fe}^{3+}$ and $\mathrm{V}^{5+}$ species of the as-prepared film remain for films polarized at or above $0.8 \mathrm{~V}$, which is commensurate with the prediction of phase stability and passivation by $\mathrm{Fe}_{2} \mathrm{O}_{3}$ in this voltage range. The films operated at -0.4 and $0 \mathrm{~V}$ contain lower-valent $\mathrm{V}$, which is commensurate with the prediction of passivation by $\mathrm{V}_{2} \mathrm{O}_{3}$ under these conditions. Overall, these experiments demonstrate 

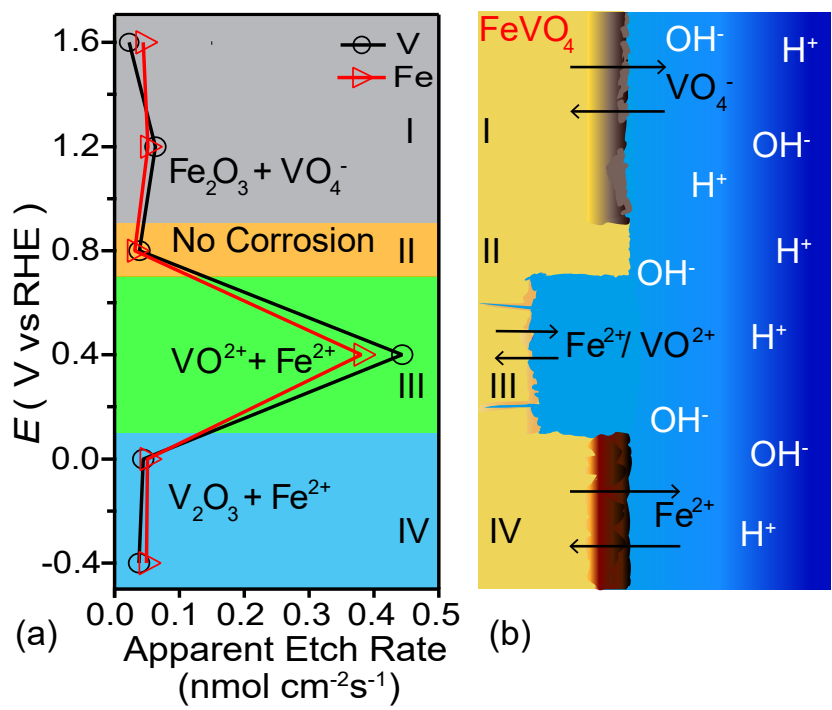

Figure 4: (Color online) (a) The etching rate of Fe and V over 15 min aqueous electrochemical operation at pH 2.9 as a function of applied potential. The calculated stable species in the 4 pertinent voltage ranges, I-IV, are shown in background color where corroding species are in bold italics. (b) A schematic of the morphology of $\mathrm{FeVO}_{4}$ in presence of water under a steady state flow of the majority ions through the solid/liquid interface in regions I-IV corresponding to the voltage ranges marked in (a).

excellent agreement with the theoretical predictions and reveal that $\mathrm{FeVO}_{4}$ does self-passivate at both low and high potential where a stable binary oxide is predicted to result from $\mathrm{FeVO}_{4}$ decomposition.

Interestingly, at the potentials of -0.4 and $0 \mathrm{~V}$, the XPS measurements show the presence of both $\mathrm{Fe}^{2+}$ and $\mathrm{Fe}^{3+}$ species (see Figure S3) in the film. The existence of $\mathrm{Fe}^{3+}$ species can be attributed to the pristine $\mathrm{FeVO}_{4}$ bulk. However, the presence of $\mathrm{Fe}^{2+}$ species cannot be attributed to the formation of the $\mathrm{V}_{2} \mathrm{O}_{3}$ passivating layers or to the $\mathrm{FeVO}_{4}$ bulk. In this context, we explain the presence of the $\mathrm{Fe}^{2+}$ species and the formation of the stable passivation layers using the concept of interfacial dissolution-precipitation processes and the Point Defect Model (PDM). ${ }^{16,59,60}$ The PDM postulates the existence of highly defective interfacial passivation layers (cation vacancies, cation interstitials, oxygen vacancies) that grow directly between the bulk and an exterior layer that forms via the hydrolysis of ions transmitted through the interfacial layer and the subsequent precipitation of a hydroxide, 
oxyhydroxide or oxide depending upon the conditions. Under steady state conditions, the thickness of the passivation layer is controlled by the standard rate constants for the generation of the defects in the interfacial layer and dissolution of ions through the interfacial and outer layers. The presence of $\mathrm{Fe}^{2+}$ in the $\mathrm{FeVO}_{4}$ samples operated at -0.4 and $0 \mathrm{~V}$ supports the interchange between the liquid and solid phase, as the stable aqueous species is $\mathrm{Fe}^{2+}$. The highly defective interfacial and outer layers could contain both $\mathrm{Fe}^{2+}$ and $\mathrm{Fe}^{3+}$ species in interstitial sites or in a locally disordered Fe-V-O phase, see voltage range IV of Figure 4(b).

According to the PDM, while the formation of the passivating layers is a highly reactive thermodynamical process, the kinetic stability of the films is obtained through a steady state of defect generation and dissolution at the solid/passivation-layer/liquid interface. PDM predicts that the passivating films on $\mathrm{FeVO}_{4}$ operated at 1.2 and $1.6 \mathrm{~V}$ are defective and disordered as well (see region I, Figure 4(b)), however, since the cations are in the same oxidations states both in the bulk material and the passivating films, XPS measurements are unable to corroborate the PDM predictions for this potential range. In total, all experimental results are commensurate with the model predictions.

\section{Summary and Conclusions}

In summary, we present a first-principles-based formalism to assess the propensity of thermodynamically stable as well as metastable materials towards electrochemical stabilization, passivation or corrosion in aqueous media. This formalism allows us to evaluate the relative Gibbs free energy, $\Delta G_{\mathrm{pbx}}$, of arbitrary materials with respect to Pourbaix stable species at any $\mathrm{pH}$, voltage, temperature and concentration of ions. Comparing with experimental reports of 20 materials (including $\mathrm{GaP}, \mathrm{Zn}\left(\mathrm{FeO}_{2}\right)_{2}$, Si, WSe $2, \mathrm{GaAs}, \mathrm{Fe}_{2} \mathrm{O}_{3}, \mathrm{WO}_{3}$ and $\mathrm{TiO}_{2}$ ) and our experimental investigations of the metastable triclinic- $\mathrm{FeVO}_{4}$, we show that materials predicted to have $\Delta G_{\mathrm{pbx}}$ up to $0.5 \mathrm{eV} /$ atom may remain stable in aqueous media, depending on the nature of their predicted decomposition products. High driving force for 
decomposition $(>0.5 \mathrm{eV})$ and/or decomposition to only aqueous species is likely to cause corrosion. On the other hand, materials that exhibit decomposition to both aqueous and solid phases can exhibit self-passivation, by forming more stable solid phases at the interface. In this context, we find an excellent agreement between experimentally measured and theoretically predicted compositions of passivation layers for materials which form passivation layers in water. Hence, the theoretical formalism presented here for estimating the electrochemical behavior of stable as well as metastable materials can be used to identify conditions under which an arbitrary materials should form passivation layers and the composition of these passivation layers. This a priori knowledge of the passivation film composition can aid in parameterizing the Point Defect Model within the corrosion community. For instance, once the passivation composition is known from our first-principles calculations, the defect diffusion rates can be computed from atomistic simulations, such as DFT and molecular dynamics simulations. These parametrized PDM can be further used to predict the passivation layer thickness and the electronic properties of the passivation layers.

Our work represents a clear advancement towards general corrosion management as well as for optimizing operating conditions of aqueous-media-based applications like photoelectrocatalysis. An open-source web-app based on the formalism is available at https://materials project.org which can be used to determine the electrochemical behavior of more than 69,000 materials available through the Materials Project database. Moreover, we make the implementation of this formalism available via the Materials Project github repository at https://github.com/materials project/pymatgen, allowing the programmatic determination of electrochemical stability of arbitrary materials not included in the Materials Project Database.

\section{Acknowledgement}

This work was primarily funded by the Joint Center for Artificial Photosynthesis, a DOE Energy Innovation Hub, supported through the Office of Science of the U.S. Department of 
Energy under Award Number DE-SC0004993. Computational work was additionally supported by the Materials Project (Grant No. EDCBEE) Predictive Modeling Center through the US Department of Energy (DOE), Office of Basic Energy Sciences, Materials Sciences and Engineering Division, under Contract DE-AC02-05CH11231. Computational resources were provided by the National Energy Research Scientific Computing Center, a DOE Office of Science User Facility supported by the Office of Science of the U.S. Department of Energy under Contract No. DE-AC02-05CH11231. The authors thank Matthias Richter for assistance with collection of XPS data.

\section{Supporting Information Available}

See supporting information for the $\mathrm{pH}$ dependent $\Delta G_{\mathrm{pbx}}$ and decomposition products of all the photoanode materials at $1.5 \mathrm{~V}$, physical vapor deposition based synthesis procedure of $\mathrm{FeVO}_{4}$, pre- and post-electrochemisty phase-identification by XRD, composition measurements by XRF and near-surface chemistry measurement by XPS. This material is available free of charge via the Internet at http://pubs.acs.org/.

\section{References}

(1) Koch, G. H.; Brongers, M. P.; Thompson, N. G.; Virmani, Y. P.; Payer, J. H. Corrosion cost and preventive strategies in the United States; 2002.

(2) Pourbaix, M. Atlas of electrochemical equilibria in aqueous solutions. 1974,

(3) Takeno, N. Atlas of Eh-pH diagrams. Geological survey of Japan open file report 2005, 419, 102.

(4) Brookins, D. G. Eh-pH diagrams for geochemistry; Springer Science \& Business Media, 2012.

(5) Persson, K. A.; Waldwick, B.; Lazic, P.; Ceder, G. Prediction of solid-aqueous equilibria: 
Scheme to combine first-principles calculations of solids with experimental aqueous states. Phys. Rev. B 2012, 85, 235438.

(6) Yan, Q.; Li, G.; Newhouse, P. F.; Yu, J.; Persson, K. A.; Gregoire, J. M.; Neaton, J. B. $\mathrm{Mn}_{2} \mathrm{~V}_{2} \mathrm{O}_{7}$ : An earth abundant light absorber for solar water splitting. Adv. Energy Mater. 2015, 5 .

(7) Zhou, L.; Yan, Q.; Yu, J.; Jones, R. J.; Becerra-Stasiewicz, N.; Suram, S. K.; Shinde, A.; Guevarra, D.; Neaton, J. B.; Persson, K. A.; Gregoire, J. M. Stability and selfpassivation of copper vanadate photoanodes under chemical, electrochemical, and photoelectrochemical operation. Phys. Chem. Chem. Phys. 2016, 18, 9349-9352.

(8) Wills, L. A.; Qu, X.; Chang, I.-Y.; Mustard, T. J.; Keszler, D. A.; Persson, K. A.; Cheong, P. H.-Y. Group additivity-Pourbaix diagrams advocate thermodynamically stable nanoscale clusters in aqueous environments. Nat. Commun. 2017, 8.

(9) Koyama, M.; Zhang, Z.; Wang, M.; Ponge, D.; Raabe, D.; Tsuzaki, K.; Noguchi, H.; Tasan, C. C. Bone-like crack resistance in hierarchical metastable nanolaminate steels. Science 2017, 355, 1055-1057.

(10) Kazemi, F.; Saberi, A.; Malek-Ahmadi, S.; Sohrabi, S.; Rezaie, H.; Tahriri, M. Novel method for synthesis of metastable tetragonal zirconia nanopowders at low temperatures. Ceram.-Silik. 2011, 55, 26-30.

(11) Singh, A. K.; Mathew, K.; Zhuang, H. L.; Hennig, R. G. Computational screening of 2D materials for photocatalysis. J. Phys. Chem. Lett. 2015, 6, 1087-1098.

(12) Luo, G.; Yang, S.; Jenness, G. R.; Song, Z.; Kuech, T. F.; Morgan, D. Understanding and reducing deleterious defects in metastable alloy GaAsBi. NPG Asia Mater. 2016, 9, e345. 
(13) Belsky, A.; Hellenbrandt, M.; Karen, V. L.; Luksch, P. New developments in the Inorganic Crystal Structure Database (ICSD): accessibility in support of materials research and design. Acta Crystallogr., Sect. B: Struct. Sci. 2002, 58, 364-369.

(14) Sun, W.; Dacek, S. T.; Ong, S. P.; Hautier, G.; Jain, A.; Richards, W. D.; Gamst, A. C.; Persson, K. A.; Ceder, G. The thermodynamic scale of inorganic crystalline metastability. Sci. Adv. 2016, 2, e1600225.

(15) Wagman, D. D.; Evans, W. H.; Parker, V. B.; Schumm, R. H.; Halow, I. The NBS tables of chemical thermodynamic properties. Selected values for inorganic and C1 and C2 organic substances in SI units; 1982.

(16) Macdonald, D. On the existence of our metals based civilization. I. Phase-space analysis. 2006. J. Electrochem. Soc. 2006, 157(7) B213-B224.

(17) Jain, A.; Ong, S. P.; Hautier, G.; Chen, W.; Richards, W. D.; Dacek, S.; Cholia, S.; Gunter, D.; Skinner, D.; Ceder, G.; Persson, K. a. The Materials Project: A materials genome approach to accelerating materials innovation. APL Mater. 2013, 1, 011002.

(18) Saal, J. E.; Kirklin, S.; Aykol, M.; Meredig, B.; Wolverton, C. Materials design and discovery with high-throughput density functional theory: the open quantum materials database (OQMD). JOM 2013, 65, 1501-1509.

(19) Curtarolo, S.; Setyawan, W.; Wang, S.; Xue, J.; Yang, K.; Taylor, R. H.; Nelson, L. J.; Hart, G. L.; Sanvito, S.; Buongiorno-Nardelli, M.; Mingo, N.; Levy, O. AFLOWLIB.ORG: A distributed materials properties repository from high-throughput ab initio calculations. Comput. Mater. Sci. 2012, 58, 227-235.

(20) Bale, C.; Bélisle, E.; Chartrand, P.; Decterov, S.; Eriksson, G.; Gheribi, A.; Hack, K.; Jung, I.-H.; Kang, Y.-B.; Melançon, J.; Peltron, A.; Petersen, S.; Robelin, C.; Sangster, J.; Spencer, P.; VanEnde, M-A. FactSage thermochemical software and databases, 2010-2016. Calphad 2016, 54, 35-53. 
(21) Johnson, J. W.; Oelkers, E. H.; Helgeson, H. C. SUPCRT92: A software package for calculating the standard molal thermodynamic properties of minerals, gases, aqueous species, and reactions from 1 to 5000 bar and 0 to 1000 C. Comput. Geosci. 1992, 18, 899-947.

(22) Ong, S. P.; Cholia, S.; Jain, A.; Brafman, M.; Gunter, D.; Ceder, G.; Persson, K. A. The Materials Application Programming Interface (API): A simple, flexible and efficient API for materials data based on REpresentational State Transfer (REST) principles. Comput. Mater. Sci. 2015, 97, 209-215.

(23) Ong, S. P.; Richards, W. D.; Jain, A.; Hautier, G.; Kocher, M.; Cholia, S.; Gunter, D.; Chevrier, V. L.; Persson, K. A.; Ceder, G. Python Materials Genomics (pymatgen): A robust, open-source python library for materials analysis. Comput. Mater. Sci. 2013, $68,314-319$.

(24) Fujishima, A.; Honda, K. Electrochemical photolysis of water at a semiconductor electrode. Nature 1972, 238, 37-38.

(25) Liu, R.; Zheng, Z.; Spurgeon, J.; Yang, X. Enhanced photoelectrochemical watersplitting performance of semiconductors by surface passivation layers. Energy Environ. Sci. 2014, 7, 2504-2517.

(26) Yourey, J. E.; Pyper, K. J.; Kurtz, J. B.; Bartlett, B. M. Chemical stability of $\mathrm{CuWO}_{4}$ for photoelectrochemical water oxidation. J. Phys. Chem. C 2013, 117, 8708-8718.

(27) Valenzuela, M.; Bosch, P.; Jiménez-Becerrill, J.; Quiroz, O.; Páez, A. Preparation, characterization and photocatalytic activity of $\mathrm{ZnO}, \mathrm{Fe}_{2} \mathrm{O}_{3}$ and $\mathrm{ZnFe}_{2} \mathrm{O}_{4}$. J. Photochem. Photobiol. , A 2002, 148, 177-182.

(28) De Haart, L.; Blasse, G. Photoelectrochemical properties of ferrites with the spinel structure. J. Electrochem. Soc. 1985, 132, 2933-2938. 
(29) Beverskog, B.; Puigdomenech, I. Revised Pourbaix diagrams for iron at $25-300{ }^{\circ} \mathrm{C}$. Corros. Sci. 1996, 38, 2121-2135.

(30) Ni, M.; Leung, M. K.; Leung, D. Y.; Sumathy, K. A review and recent developments in photocatalytic water-splitting using $\mathrm{TiO}_{2}$ for hydrogen production. Renewable Sustainable Energy Rev. 2007, 11, 401-425.

(31) Hu, S.; Shaner, M. R.; Beardslee, J. A.; Lichterman, M.; Brunschwig, B. S.; Lewis, N. S. Amorphous $\mathrm{TiO}_{2}$ coatings stabilize Si, GaAs, and GaP photoanodes for efficient water oxidation. Science 2014, 344, 1005-1009.

(32) Tang, D.; Mabayoje, O.; Lai, Y.; Liu, Y.; Mullins, C. B. Enhanced Photoelectrochemical Performance of Porous $\mathrm{Bi}_{2} \mathrm{MoO}_{6}$ Photoanode by an Electrochemical Treatment. J. Electrochem. Soc. 2017, 164, H299-H306.

(33) Zhang, L.; Baumanis, C.; Robben, L.; Kandiel, T.; Bahnemann, D. Bi ${ }_{2} \mathrm{WO}_{6}$ Inverse Opals: Facile Fabrication and Efficient Visible-Light-Driven Photocatalytic and Photoelectrochemical Water-Splitting Activity. Small 2011, 7, 2714-2720.

(34) Chen, X.; Yu, T.; Gao, F.; Zhang, H.; Liu, L.; Wang, Y.; Li, Z.; Zou, Z.; Liu, J.-M. Application of weak ferromagnetic $\mathrm{BiFeO}_{3}$ films as the photoelectrode material under visible-light irradiation. Appl. Phys. Lett. 2007, 91, 022114.

(35) Moniz, S. J.; Quesada-Cabrera, R.; Blackman, C. S.; Tang, J.; Southern, P.; Weaver, P. M.; Carmalt, C. J. A simple, low-cost CVD route to thin films of $\mathrm{BiFeO}_{3}$ for efficient water photo-oxidation. J. Mater. Chem. A 2014, 2, 2922-2927.

(36) Tolod, K. R.; Hernández, S.; Russo, N. Recent advances in the $\mathrm{BiVO}_{4}$ photocatalyst for sun-driven water oxidation: Top-performing photoanodes and scale-up challenges. Catalysts 2017, 7, 13. 
(37) Sayama, K.; Nomura, A.; Zou, Z.; Abe, R.; Abe, Y.; Arakawa, H. Photoelectrochemical decomposition of water on nanocrystalline $\mathrm{BiVO}_{4}$ film electrodes under visible light. Chem. Commun. 2003, 2908-2909.

(38) Toma, F. M. et al. Mechanistic insights into chemical and photochemical transformations of bismuth vanadate photoanodes. Nat. Commun. 2016, 7.

(39) Courtin, E.; Baldinozzi, G.; Sougrati, M. T.; Stievano, L.; Sanchez, C.; LabertyRobert, C. New $\mathrm{Fe}_{2} \mathrm{TiO}_{5}$-based nanoheterostructured mesoporous photoanodes with improved visible light photoresponses. J. Mater. Chem. A 2014, 2, 6567-6577.

(40) Doumerc, J.-P.; Hejtmanek, J.; Chaminade, J.-P.; Pouchard, M.; Krussanova, M. A photoelectrochemical study of $\mathrm{CuWO}_{4}$ single crystals. Phys. Status Solidi A 1984, 82, $285-294$.

(41) Nandjou, F.; Haussener, S. Degradation in photoelectrochemical devices: review with an illustrative case study. J. Phys. D: Appl. Phys. 2017, 50, 124002.

(42) Tang, D.; Rettie, A. J.; Mabayoje, O.; Wygant, B. R.; Lai, Y.; Liu, Y.; Mullins, C. B. Facile growth of porous $\mathrm{Fe}_{2} \mathrm{~V}_{4} \mathrm{O}_{13}$ films for photoelectrochemical water oxidation. $J$. Mater. Chem. A 2016, 4, 3034-3042.

(43) Seabold, J. A.; Neale, N. R. All first row transition metal oxide photoanode for water splitting based on $\mathrm{Cu}_{3} \mathrm{~V}_{2} \mathrm{O}_{8}$. Chem. Mater. 2015, 27, 1005-1013.

(44) Kalal, S.; Pandey, A.; Ameta, R.; Punjabi, P. B. Heterogeneous photo-Fenton-like catalysts $\mathrm{Cu}_{2} \mathrm{~V}_{2} \mathrm{O}_{7}$ and $\mathrm{Cr}_{2} \mathrm{~V}_{4} \mathrm{O}_{13}$ for an efficient removal of azo dye in water. Cogent Chem. 2016, 2, 1143344.

(45) Mandal, H.; Shyamal, S.; Hajra, P.; Bera, A.; Sariket, D.; Kundu, S.; Bhattacharya, C. Development of ternary iron vanadium oxide semiconductors for applications in photoelectrochemical water oxidation. $R S C A d v$. 2016, 6, 4992-4999. 
(46) Morton, C. D.; Slipper, I. J.; Thomas, M. J.; Alexander, B. D. Synthesis and characterisation of Fe-V-O thin film photoanodes. J. Photochem. Photobiol., A 2010, 216, $209-214$.

(47) Guo, W.; Chemelewski, W. D.; Mabayoje, O.; Xiao, P.; Zhang, Y.; Mullins, C. B. Synthesis and characterization of $\mathrm{CuV}_{2} \mathrm{O}_{6}$ and $\mathrm{Cu}_{2} \mathrm{~V}_{2} \mathrm{O}_{7}$ : Two photoanode candidates for photoelectrochemical water oxidation. J. Phys. Chem. C 2015, 119, 27220-27227.

(48) Tenne, R.; Wold, A. Passivation of recombination centers in $n$-WSe 2 yields high efficiency $(>14 \%)$ photoelectrochemical cell. Appl. Phys. Lett. 1985, 47, 707-709.

(49) Meissner, D.; Benndorf, C.; Memming, R. Photocorrosion of cadmium sulfide: Analysis by photoelectron spectroscopy. Appl. Surf. Sci. 1987, 27, 423-436.

(50) Yamada, S.; Nosaka, A. Y.; Nosaka, Y. Fabrication of CdS photoelectrodes coated with titania nanosheets for water splitting with visible light. J. Electroanal. Chem. 2005, 585, 105-112.

(51) Schmuki, P.; Sproule, G.; Bardwell, J.; Lu, Z.; Graham, M. Thin anodic oxides formed on GaAs in aqueous solutions. J. Appl. Phys. 1996, 79, 7303-7311.

(52) Wang, H.-H.; Wu, J.-Y.; Wang, Y.-H.; Houng, M.-P. Effects of pH Values on the Kinetics of Liquid-Phase Chemical-Enhanced Oxidation of GaAs. J. Electrochem. Soc. 1999, 146, 2328-2332.

(53) Lee, M. H.; Takei, K.; Zhang, J.; Kapadia, R.; Zheng, M.; Chen, Y.-Z.; Nah, J.; Matthews, T. S.; Chueh, Y.-L.; Ager, J. W.; Javey, A. p-Type InP Nanopillar Photocathodes for Efficient Solar-Driven Hydrogen Production. Angew. Chem., Int. Ed. 2012, 51, 10760-10764.

(54) Radhakrishnan, B.; Ong, S. P. Aqueous stability of alkali superionic conductors from first-principles calculations. Frontiers in Energy Research 2016, 4, 16. 
(55) Lian, X.; Xiao, P.; Liu, R.; Henkelman, G. Calculations of oxygen adsorption-induced surface reconstruction and oxide formation on $\mathrm{Cu}$ (100). Chem. Mater. 2017, 29, 14721484.

(56) Duan, Z.; Henkelman, G. CO oxidation on the Pd (111) surface. ACS Catal. 2014, 4, $3435-3443$.

(57) Barmak, K.; Liu, J.; Harlan, L.; Xiao, P.; Duncan, J.; Henkelman, G. Transformation of topologically close-packed $\beta$-W to body-centered cubic $\alpha$-W: Comparison of experiments and computations. J. Chem. Phys. 2017, 14\%, 152709.

(58) Guo, Y.; Sun, D.; Ouyang, B.; Raja, A.; Song, J.; Heinz, T. F.; Brus, L. E. Probing the dynamics of the metallic-to-semiconducting structural phase transformation in MoS2 crystals. Nano Lett. 2015, 15, 5081-5088.

(59) Macdonald, D. D. Theory of passive film stability. ECS Trans. 2007, 2, 73-81.

(60) Obot, I.; Macdonald, D.; Gasem, Z. Density functional theory (DFT) as a powerful tool for designing new organic corrosion inhibitors. Part 1: an overview. Corros. Sci. 2015, 99, 1-30. 


\section{Graphical TOC Entry}

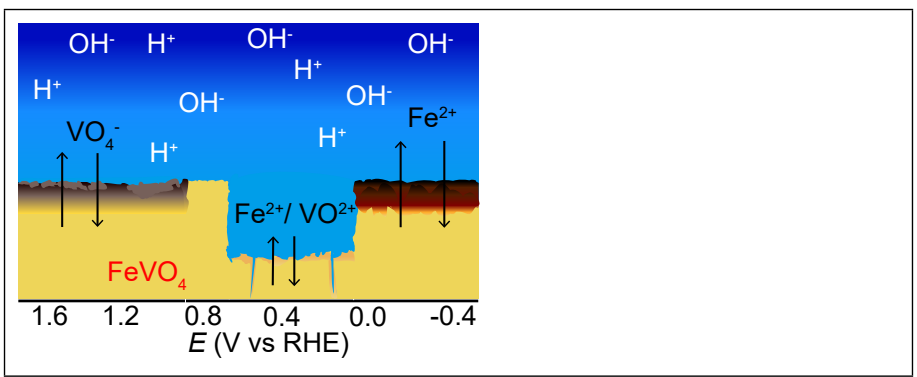

16

17

18

19

20

21

22

23

24

25

26

27

28

29

30

31

32

33

34

35

36

37

38

39

40

41

42

43

44

45

46

47

48

49

50

51

52

53

54

55

56

57

58

59

60 


\section{$\begin{array}{lll}\mathrm{OH}^{-} & \mathrm{H}^{+} & \mathrm{OH}^{-}\end{array}$}

\section{$\mathrm{OH}^{-}$}

$\mathrm{H}^{+}$Chemistry Pofigttarerofils0 $\mathrm{H}^{+} \mathrm{OH}^{-} \mathrm{OH}^{-} \mathrm{Ce}^{2+}$

$\mathrm{VO}_{4}^{-}$

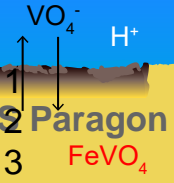

$\mathrm{H}^{+}$ $\mathrm{Fe}^{2+}$

C2 Paragon $\mathrm{Fe}^{2+} / \mathrm{VO}^{2+}$ $3 \quad \mathrm{FeVO}_{4}$

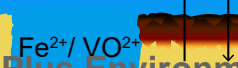
1401.2
0.8
0.4
0.0
$-0.4$
5
$E(\mathrm{~V}$ vs RHE) 